\title{
Heuristic remedial actions in the reliability assessment of high voltage direct current networks
}

\author{
Mario A. Rios, Maria F. Perez \\ Department of Electrical Engineering and Electronics, School of Engineering, Universidad de los Andes, Bogota, \\ Colombia
}

\begin{tabular}{l} 
Article Info \\
\hline Article history: \\
Received Jul 9, 2020 \\
Revised Apr 24, 2021 \\
Accepted May 21, 2021 \\
\hline
\end{tabular}

Keywords:

Availability assessment HVDC grids

Reliability of power systems

\begin{abstract}
Planning of high voltage direct current (HVDC) grids requires inclusion of reliability assessment of alternatives under study. This paper proposes a methodology to evaluate the adequacy of voltage source converter/VSCHVDC networks. The methodology analyses the performance of the system using $\mathrm{N}-1$ and $\mathrm{N}-2$ contingencies in order to detect weaknesses in the DC network and evaluates two types of remedial actions to keep the entire system under the acceptable operating limits. The remedial actions are applied when a violation of these limits on the DC system occurs; those include topology changes in the network and adjustments of power settings of VSC converter stations. The CIGRE B4 DC grid test system is used for evaluating the reliability/adequacy performance by means of the proposed methodology in this paper. The proposed remedial actions are effective for all contingencies; then, numerical results are as expected. This work is useful for planning and operation of grids based on VSC-HVDC technology.
\end{abstract}

This is an open access article under the CC BY-SA license.

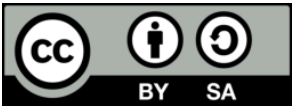

\author{
Corresponding Author: \\ Mario Alberto Rios \\ Department of Electrical Engineering and Electronics \\ School of Engineering \\ Universidad de los Andes \\ Carrera 1 No. 18 A - 12, Bogota, Colombia \\ Email: mrios@uniandes.edu.co
}

\section{INTRODUCTION}

With the increase of power demand and the need of integration of renewable energy sources (wind and solar), reinforcements are required in the AC system and, often, the traditional approach is to build new AC lines. However, this solution could bring different kinds of problems that lead to large time consumption and even to the denial of permissions to build new overhead lines. This problem might be solved by replacing current AC lines with new DC lines, which do not require additional rights-of-way and increase the transmission capability [1], [2].

High voltage direct current (HVDC) technology allows transmitting more power over longer distances using fewer lines than the ones needed for AC transmission. This alternative has several advantages such as narrower rights-of-way, lower line losses, more reliable system operation, and lower costs. Furthermore, interconnections between asynchronous networks with HVDC transmission systems are an alternative to be considered [3]. In addition, large integrations of renewable sources and the integration of large power systems are conducting to the development of HVDC grids [4] or SuperGrids [5].

HVDC based on voltage source converter (VSC) technology is considered as the most appropriate technology for multi-terminal applications [6], as the development of HVDC-Grids that allows making parallel HVDC configurations, control both power flows and flow directions [5]. As [5] mentions, multi- 
terminal LCC-HVDC or HVDC grids based on LCC technology might result in an unreliable systems when constant changing power flows are required.

With the increase of power demand and the need of integration of renewable energy sources (wind and solar), reinforcements are required in the AC system and, often, the traditional approach is to build new AC lines. However, this solution could bring different kinds of problems that lead to large time consumption and even to the denial of permissions to build new overhead lines. This problem might be solved by replacing current AC lines with new DC lines, which do not require additional rights-of-way and increase the transmission capability [1], [2]

HVDC technology allows transmitting more power over longer distances using fewer lines than the ones needed for AC transmission. This alternative has several advantages such as narrower rights-of-way, lower line losses, more reliable system operation, and lower costs. Furthermore, interconnections between asynchronous networks with HVDC transmission systems are an alternative to be considered [3]. In addition, large integrations of renewable sources and the integration of large power systems are conducting to the development of HVDC grids [4] or SuperGrids [5].

HVDC based on voltage source converter (VSC) technology is considered as the most appropriate technology for multi-terminal applications [6], as the development of HVDC-Grids that allows making parallel HVDC configurations, control both power flows and flow directions [5]. As [5] mentions, multiterminal LCC-HVDC or HVDC grids based on LCC technology might result in an unreliable systems when constant changing power flows are required.

Evaluation of the reliability of a power system is generally used to assess the probability of supplying power at a given load point in an appropriate manner. Therefore, such assessment is important during the electrical grid planning stage as a decision-making tool [7], [8]. A contingency of a HVDC line or a converter station in an HVDC grid system causes major perturbations and negative economic impacts. Thus, a reliability evaluation in planning studies becomes essential [9].

The typical reliability analysis of HVDC systems focuses on evaluating the reliability performance of a HVDC link; but not for evaluating the performance of a HVDC grid. Thus, Guo et al. [10] present a reliability assessment of HVDC transmission system applying the frequency and duration (F\&D) method. In this method, a reliability model for modular multilevel converter (MMC) and cascade two-level (CTL) topologies is developed in detail. Li et al. [11] uses also F\&D method to evaluate the reliability of UHVDC converter stations and propose some reliability indices associated to the energy availability to both sides of a HVDC link. In [12], an analytical method and a Monte Carlo simulation method are used to calculate the reliability indices and compare three different topologies of VSC-HVDC distribution systems. This study concluded that a high failure rate of converters controls the system reliability index, with the system topology going into the background. Linden et al. [13] presents a study of reliability performance of bipolar HVDC connection and three point-to-point EHVAC connections and identification of fault combinations that have a strong impact on the system reliability.

Rios et al. [14] proposes a method of computing the availability of HVDC grids based on remedial actions computed by application of optimal power flow. Nevertheless, the optimal power flow is an algorithm that demands high computation-time; in addition, the operation of the system must take rapid actions when disturbances are present. In such case, computation of an optimal power flow could be the nomore effective computation tool of remedial actions. Then, computation of corrective actions based on heuristic are an alternative for fast decision in the operation of a HVDC grid.

This paper presents a modification of computation of remedial actions based on heuristic actions in order to improve computation time. Section 2.1 presents a synthesis of the methodology of reliability assessment proposed in [14] based on state enumeration methods and N-2 contingency analysis; while section 2.2 proposes two types of remedial actions to maintain system-operating limits when the outage of components of the HVDC grid occur. The proposed methods are the main contribution of this paper. In addition, section 2.2 shows the technical results as the proposed algorithms for general and particular remedial actions and the mathematical methods of these corrective actions. Section 2.3 describes the reliability indices used. Then, the proposed methodology is applied to the CIGRE B4 Grid Test System using MatACDC [15] (section 3). Finally, section 4 presents the conclusions.

\section{RESEARCH METHOD}

\subsection{Reliability assessment of VSC-HVDC networks}

A VSC-HVDC consists of several converter stations (rectifiers and inverters), HVDC lines and DC transformers [5] or DC hubs. Each converter station includes its AC transformers, phase reactors, breakers and DC capacitors, switchgear, a VSC DC/AC converter based on IGBTs technology [5]. All these elements 
are required for the correct operation of the station. The other important component is the HVDC line, and according to the stations configurations, the HVDC lines in the grid are monopolar or bipolar.

For reliability assessment of the HVDC grid, when a fault in a single pole component (converter station or line) occurs, the component is put out of service. In the case of bipolar components, a fault put out of service the pole where the fault occurs; in this case, the other pole of the component maintains in operation. In [16]-[18] present data about the failure rate and mean time to repair (MTTR) for overhead HVDC lines, for undersea HVDC cables, and for converter stations.

The purpose of a DC transformer is to interconnect two DC networks of different voltage. It consists of a rectifier station, and AC transformer and an inverter station whose purpose [5], [19]. The utilization of DC/DC converter stations or DC/DC hubs is another alternative for this task [19].

The model of all these components for reliability assessment consists of a two-state model: up and down, like it is used in the composite AC power system [20]. The transitions between these states for the component $i$ are modelled by its equivalent failure rate $\left(\lambda_{i}\right)$ and the equivalent repair rate $\left(\mu_{i}\right)$. Thus, the forced outage rate of component $i$ of the grid is (1):

$$
F O R_{i}=\frac{\lambda_{i}}{\lambda_{i}+\mu_{i}}
$$

The reliability assessment is made by the truncated state enumeration method, which consists of count all possible system states taking a maximum number of simultaneous out-of-service components. Typically, a criterion of N-2 that considers maximum two failed components is used [21], [22]. The system state probability $P(S)$ is $(2)$ :

$$
P(S)=\prod_{j=1}^{m} P r_{j} \prod_{i=1}^{n-m} Q_{i}
$$

where $P r_{j}$ is the working probability of the $j$ th component, $Q_{i}=1-P r_{i}$ is the failure probability of the $i$ th component, $n$ is the number of components, $m$ is the number of working components, and $n-m$ is the number of failed components. The performance of each state is evaluated in order to assess if it satisfies the operating criteria: non-overload of components and non-voltage violation in DC nodes. If any criterion is not satisfied, remedial actions are computed (see section 2.2).

\subsection{Remedial actions of operational states under contingencies}

In the adequacy assessment of bulk power systems (AC) there have been two trends for the realization of remedial actions; one, implemented in a lot of commercial software, is load curtailment in percentage steps until the system satisfies the operating criteria. This strategy is not appropriate for the HVDC grid, taking into account that a station does not necessarily meet a specific load but the exchange of power of an AC system with the HVDC-grid may be attending with other stations DC. Then, a strategy to adjust the set points of the conversion stations is more appropriate. This scheme simulates short-term corrective actions that would be in the network.

Remedial actions are a heuristic applied to fulfil the N-2 criteria and to maintain system-operating limits; these are non-overload branches (by pole) and DC voltage between 0.95 p.u. and 1.05 p.u.; similar to the AC system [23]. Then, general and particular remedial actions include topology changes in the HVDC grid and adjustments in the power flow settings of the converter stations. The remedial actions are applied in three stages:

a. Verification of power flow convergence,

b. Identification of violated operating limits and,

c. Application of appropriate corrective action for resolving violated limits [24].

\subsubsection{General remedial actions}

A general remedial action consist of two alternatives: a gradual reduction, in the same proportion, of the power supplied by all converter stations or a topology change by disconnection of DC converter stations and/or DC lines. They are applied when a contingency occurs, and power flow analysis fails to converge. If after the gradual reduction of DC converter stations power, the power flow study is still failing to convergence then a topology change of the grid is required. Figure 1 shows the overall procedure. 


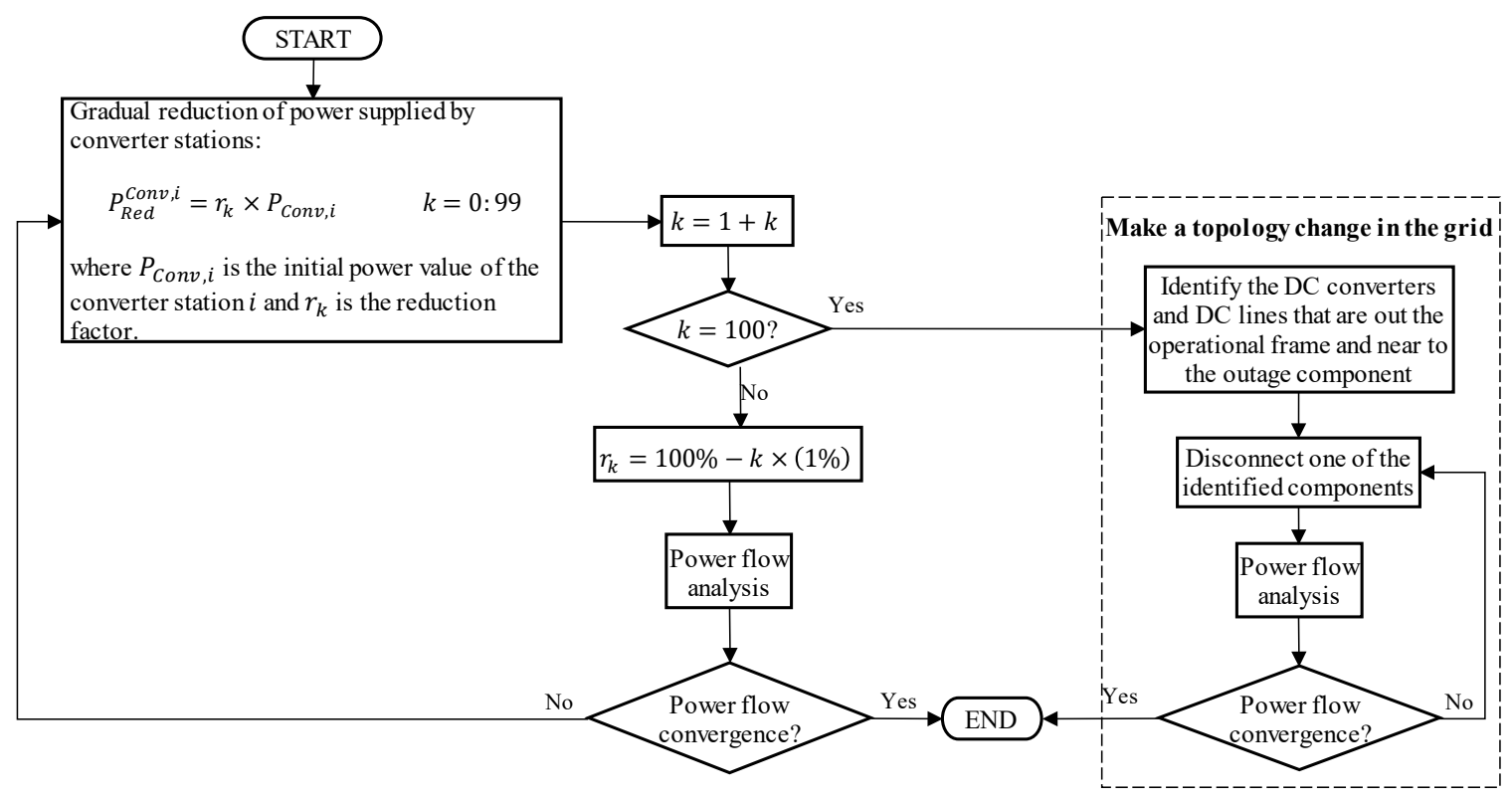

Figure 1. General remedial actions for VSC-HVDC transmission grids

\subsubsection{Particular remedial actions}

A particular remedial action is applied when a system operating limit violation occurs. This action consists of three stages which are applied sequentially. The overall procedure is as follows:

Stage 1. Arithmetic adjustment of the power supplied by the DC converter stations.

Figure 2(a) illustrates an outage of a converter station $\mathrm{C}_{0}$ connecting the $\mathrm{DC}$ grid $\mathrm{D}{ }_{0}$ with the zone $\mathrm{ZA}_{0}$ of the AC grid. The converter station outage causes a power unbalance $P_{0}$ in the DC grid and in the connected $\mathrm{AC}$ grid. As the converter $C_{0}$ is an extraction power converter, then each of the remaining working extraction power converters linked to the same AC zone $Z A_{0}$ will contribute with an equal fraction of $P_{0}$. The new power values of the converters can be simple calculated ( 3 ):

$$
\hat{P}_{i}=P_{i}+\frac{P_{0}}{m}
$$

where $m$ is the number of working extraction power converters linked to the AC zone $Z A_{0}$ to which the outaged converter belongs; $P_{i}$. is the power supplied by the converter in normal operating conditions; $P_{0}$ is the power supplied by the outaged converter after the contingency; and $\hat{P}_{i}$ is the new power that will be supplied by the converter. If $\hat{P}_{i}$ is greater than the maximum nominal power that can be supplied by the converter then $\hat{P}_{i}$ is fixed to the maximum power value. The procedure described above can be followed when there is an outage of an injection power converter. An arithmetic adjustment of the power supplied by the DC converter stations for the contingency shown in Figure 2(a) is illustrated in Figure 2(b).

When an outage of a DC line occurs, the power unbalance is given by the DC converter station that must reduce its supplied power for managing the imbalance. In this case, the adjustment of the power is made following the same procedure applied when there is an outage of a DC converter station, however now $P_{0}$ is the power given by (4):

$$
P_{0}=P_{0}^{\text {nom }}-P_{0}^{r e d}
$$

where $P_{0}^{\text {nom }}$ is the power supplied by the converter in normal operating conditions and $P_{0}^{\text {red }}$ is the reduced power supplied by the converter due to the outage of a DC line.

Stage 2. Analytical adjustment of the power supplied by the DC converter stations.

If the system operating limit violation persists after applying the power adjustment described in Stage 1, a reduction of the power supplied by the converter stations shall be made. In Figure 2(a), the outaged converter $C_{0}$ is an extraction power converter linked to the $\mathrm{AC}$ zone $Z A_{0}$ and $\mathrm{DC}$ grid $G D_{0}$ then the power supplied by each working injection power converter linked to $G D_{0}$ will be reduced. The new power values of the converters can be calculated (5): 


$$
\vec{P}_{a}^{c o n v}=G_{u p} \overrightarrow{\widehat{V}} \rightarrow\left[\begin{array}{c}
\hat{P}_{1} \\
\vdots \\
\hat{P}_{N_{1}}
\end{array}\right]=\left[\begin{array}{ccc}
G_{1,1} & \cdots & G_{1, N} \\
\vdots & \ddots & \vdots \\
G_{N_{1}, 1} & \cdots & G_{N_{1}, N}
\end{array}\right]\left[\begin{array}{c}
\hat{V}_{1} \\
\vdots \\
\hat{V}_{N_{1}} \\
\widehat{V}_{N_{1}+1} \\
\vdots \\
\hat{V}_{N}
\end{array}\right]
$$

where $\vec{P}_{a}^{c o n v}$ is the vector of new values of power injections; $G_{u p}$ is the upper square sub-matrix of the admittance matrix that corresponds to all the injection power buses link to DC grid $G D_{0} ; N_{1}$ is the number of injection power converters linked to $G D_{0} ; N$ is the number of extraction power converters linked to $G D_{0}$; and $\vec{V}$ is the vector of converter voltages given by (6):

$$
\overrightarrow{\hat{I}}^{\text {conv }}=G_{\text {low }} \overrightarrow{\hat{V}} \rightarrow\left[\begin{array}{c}
I_{N_{1}+1} \\
\vdots \\
\hat{I}_{0} \\
\hat{I}_{i} \\
\vdots \\
\hat{I}_{m} \\
\vdots \\
I_{N}
\end{array}\right]=\left[\begin{array}{ccc}
G_{N_{1}+1,1} & \cdots & G_{N_{1}+1, N} \\
\vdots & \ddots & \vdots \\
G_{N, 1} & \cdots & G_{N, N}
\end{array}\right]\left[\begin{array}{c}
\hat{V}_{1} \\
\vdots \\
\hat{V}_{N_{1}} \\
\hat{V}_{N_{1}+1} \\
\vdots \\
\hat{V}_{N}
\end{array}\right]
$$

where $G_{\text {low }}$ is the lower square sub-matrix of the admittance matrix that corresponds to all the extraction power buses link to DC grid $G D_{0}$, and $\overrightarrow{\hat{I}}^{\text {conv }}$ is the vector of currents of extraction power converters given by (7):

$$
\vec{P}_{b}^{c o n v}=\vec{V} \otimes \overrightarrow{\hat{I}}^{\text {conv }} \rightarrow\left[\begin{array}{c}
P_{N_{1}+1} \\
\vdots \\
\hat{P}_{0} \\
\hat{P}_{i} \\
\vdots \\
\hat{P}_{m} \\
\vdots \\
P_{N}
\end{array}\right]=\left[\begin{array}{c}
V_{N_{1}+1} \\
\vdots \\
V_{0} \\
V_{i} \\
\vdots \\
V_{m} \\
\vdots \\
V_{N}
\end{array}\right] \otimes\left[\begin{array}{c}
I_{N_{1}+1} \\
\vdots \\
\hat{I}_{0} \\
\hat{I}_{i} \\
\vdots \\
\hat{I}_{m} \\
\vdots \\
I_{N}
\end{array}\right]
$$

where $\overrightarrow{\hat{P}}_{b}^{\text {conv }}$ is the vector of new values of power extractions obtained in Stage 1 and the power supplied by the extraction power converters in normal operating conditions; $\vec{V}$ is the vector of converter voltages in normal operating conditions; and $m$ is the number of working extraction power converters linked to DC grid $G D_{0}$. The power supplied by the outaged converter is $\hat{P}_{0}=0$.

If $\overrightarrow{\hat{P}}_{a}^{\text {conv }}$ and/or $\overrightarrow{\hat{P}}_{b}^{\text {conv }}$ are greater than the maximum nominal power that can be supplied by the converter then $\overrightarrow{\hat{P}}_{a}^{\text {conv }}$ and $\overrightarrow{\hat{P}}_{b}^{\text {conv }}$ are fixed to the maximum power value. The procedure described above can be followed when there is an outage of an injection power converter. An analytical adjustment of the power supplied by the DC converter stations for the contingency shown in Figure 2, is illustrated in Figure 3.

When an outage of a DC line occurs the analytical adjustment of the power is made following the same procedure applied when there is an outage of a DC converter station; however, in (7) $\hat{P}_{0}$ is the power described by (4).

Stage 3. Power balance in DC network.

If the system operating limit violation persists after applying the analytical power adjustment described in Stage 2, a balance between power injected and power extracted to or from the DC grid shall be made. In Figure 2, the outaged converter $C_{0}$ is linked to the DC grid $G D_{0}$ and working extraction and injections power converters are also linked. The power unbalance $\Delta P$ in $G D_{0}$ is as (8):

$$
\Delta P=\left(\sum_{j} P_{i n j, j}+P_{\text {Loss }}\right)-\sum_{i} P_{e x t, i}
$$

where $P_{\text {ext }, i}$ is the power extracted from the DC grid $G D_{0}$ by the $i$ th extraction power converter; $P_{i n j, j}$ is the power injected to the DC grid $G D_{0}$ by the $j$ th injection power converter; and $P_{\text {Loss }}$ is total DC grid $G D_{0}$. power losses. 
If $\Delta P$ is greater than 0 then an adjustment of the power supplied by the injection power converters shall be made, but if $\Delta P$ is less than 0 , then the power adjustment shall be made by the extraction power converters. The unbalance is corrected when $\Delta P$ is equal to 0 . The power unbalance $\Delta P$ is distributed in a proportional way, then new power values of the converters $\hat{P}_{k}^{\text {conv }}$ can be simple calculated (9):

$$
\hat{P}_{k}^{\text {conv }}=P_{k}^{\text {conv }}-P_{k}^{c o n v} \frac{|\Delta P|}{P_{T}^{c o n v}}
$$

where $P_{k}^{\text {conv }}$ is the adjusted power given by $\overrightarrow{\hat{P}}_{a}^{\text {conv }}$ and $\overrightarrow{\hat{P}}_{b}^{\text {conv }}$ obtained in Stage 2 and $P_{T}^{\text {conv }}$ is the total power supplied by all extraction or injection power converters linked to the DC grid $G D_{0}$. The overall procedure that includes these stages is illustrated in Figure 4.

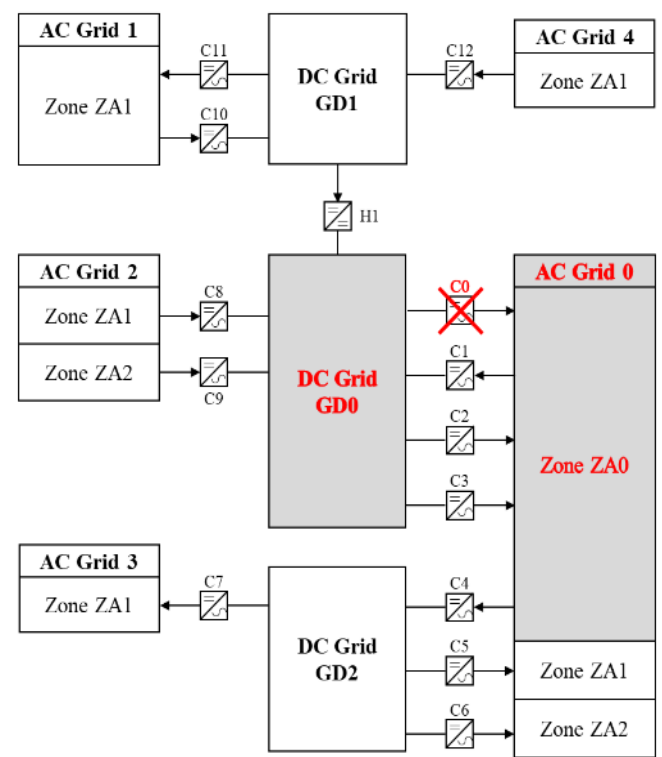

(a)

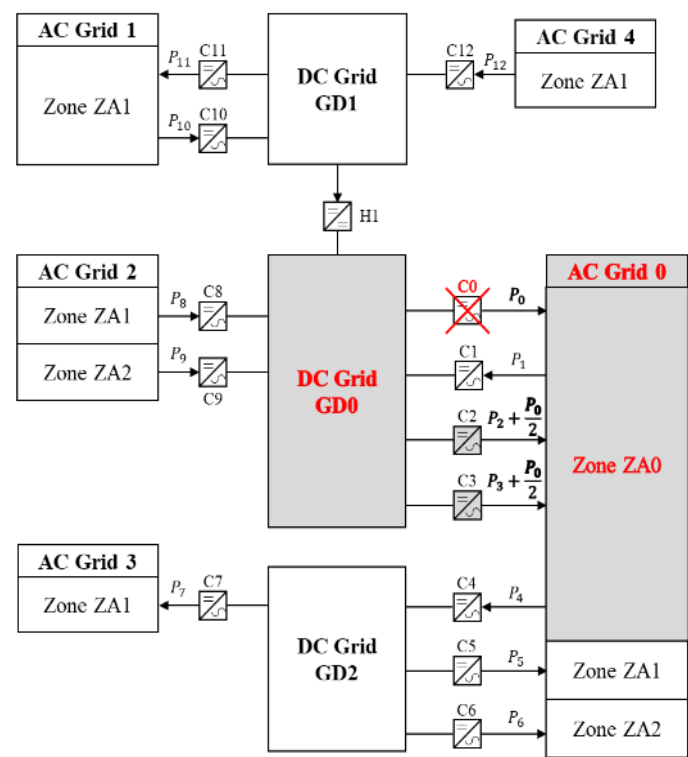

(b)

Figure 2. Outage of a DC converter station-Stage 1: arithmetic adjustment of converters power, a) outage of a DC converter station, and b) addressing an outage of a DC converter station

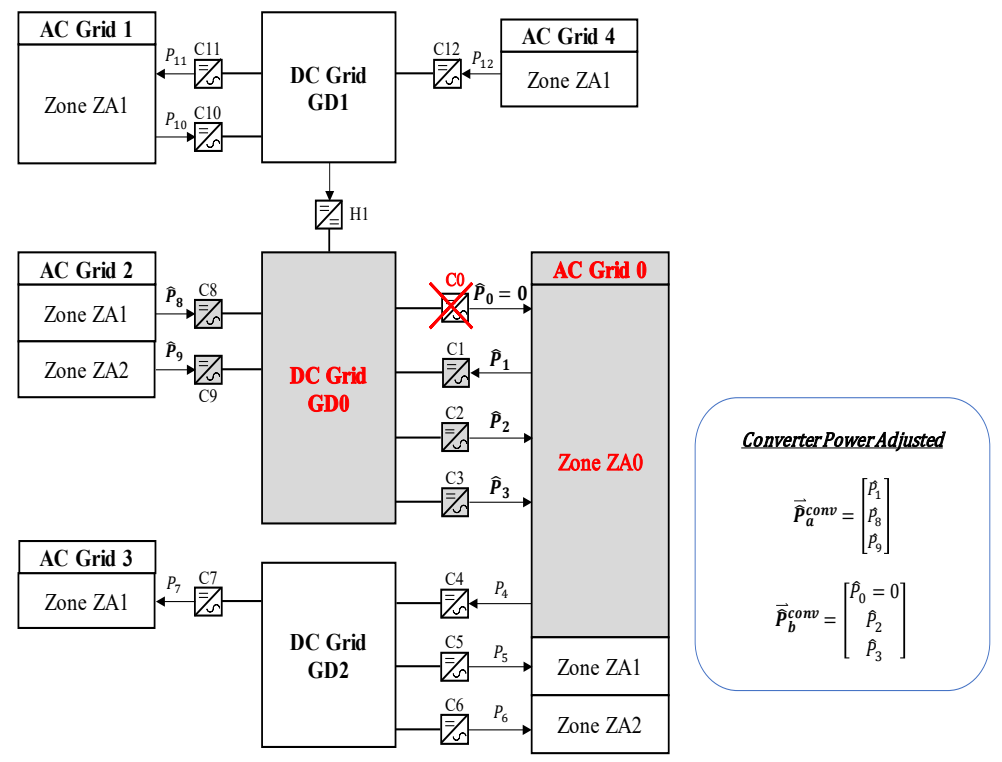

Figure 3. Stage 2: Analytical adjustment of converter power stations 


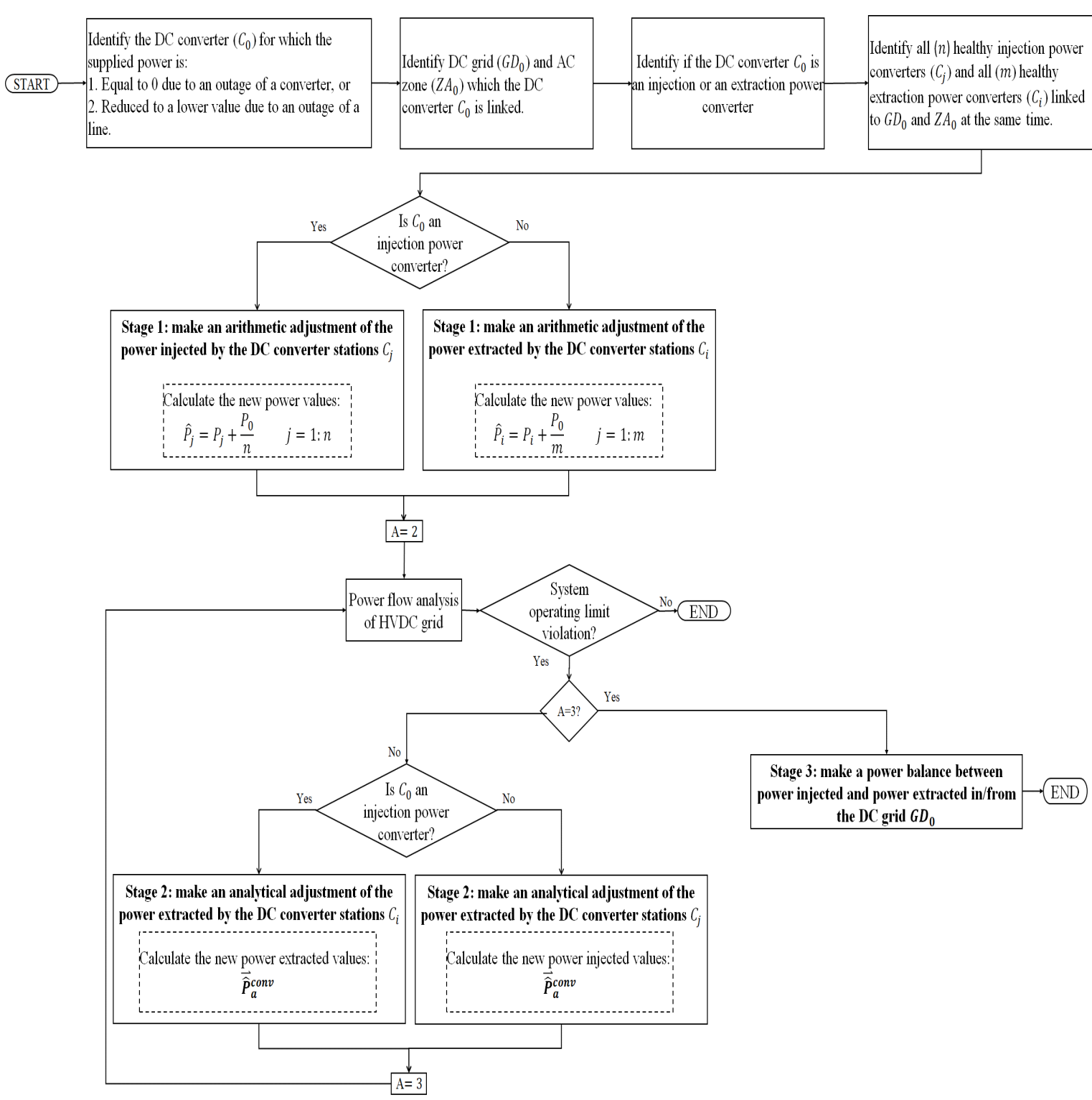

Figure 4. Particular remedial actions for VSC-HVDC transmission grids

\subsection{Reliability indices for HVDC networks}

Rios et al. [14] defines reliability indices applied for adequacy assessment of HVDC grids. Traditional AC reliability indices computes nodal indexes. A deficiency into supply power to a specific AC node implies loss of load in this node. However, taking into account that for a certain AC system the supply from a HVDC-grid can be made for different interconnection converter stations, but the important reliability objective is to provide the total interchange (power balance) between the HVDC-grid and the specific AC area; that is the case for areas ZA0 and ZA1 in Figure 3. In the case of AC areas that supply power to other systems through the HVDC-grid (i.e. areas that export power) the most important is to assess the availability to make the power exportation by the different available connection points; as it is the case for area "AC Grid 2" in Figure 3.

Thus, the reliability indices defined by [14] are classified in two sets: i) loss of power and energy extracted from DC grid to AC zones as shown in Table 1, and ii) loss of power and energy injected to the AC zones from the DC grid as shown in Table 2. As global or system indices, the adequacy indices of Table 1 are computed to level system. Additionally, an energy index of reliability (EIR $\mathrm{DC}_{\mathrm{C}}$ ) defined as the percentage (\%) between the energy effectively transmitted from the $\mathrm{DC}$ grid to the $\mathrm{AC}$ zones and the total energy required by the DC system [14]. 
Table 1. Definition of reliability indices for HVDC grids-extraction zones

\begin{tabular}{ll}
\hline \multicolumn{1}{c}{ Indices } & \multicolumn{1}{c}{ Definition } \\
\hline Loss of power extraction probability (LOPEP) & $\begin{array}{l}\text { Probability of power extraction form DC grid to AC networks larger } \\
\text { than nominal capabilities when a contingency occurs. }\end{array}$ \\
Expected number of power extraction reduction (ENPER) & $\begin{array}{l}\text { Number of times that a reduction on power extractions from the DC } \\
\text { grid to AC networks are required. }\end{array}$ \\
The expected value of power extraction not transmitted from the DC \\
grid to the AC zones. \\
The expected annual energy not transmitted from the DC grid to the \\
AC zone.
\end{tabular}

Table 2. Definition of reliability indices for HVDC grids-injection zones

\begin{tabular}{ll}
\hline \multicolumn{1}{c}{ Indices } & \multicolumn{1}{c}{ Definition } \\
\hline Loss of power injection probability (LOPIP) & $\begin{array}{l}\text { Probability of power injections to the DC grid from AC networks are } \\
\text { larger than nominal capabilities when a contingency occurs. }\end{array}$ \\
Expected number of power injection reduction (ENPIR) & $\begin{array}{l}\text { Number of times that a reduction on power injections to the DC grid } \\
\text { from the AC networks are required. } \\
\text { The expected value of power injection not transmitted to the DC grid } \\
\text { from the AC zones. } \\
\text { The expected annual energy not transmitted to the DC grid from the } \\
\text { AC zone }\end{array}$ \\
&
\end{tabular}

\section{RESULTS AND ANALYSIS}

\subsection{Study system}

The CIGRE B4 DC network test system [25], [26] is used for computing the reliability performance based on the proposed methodology of this paper. The power flow analysis of CIGRE B4 DC test system as shown in Figure 5 are run with MatACDC.

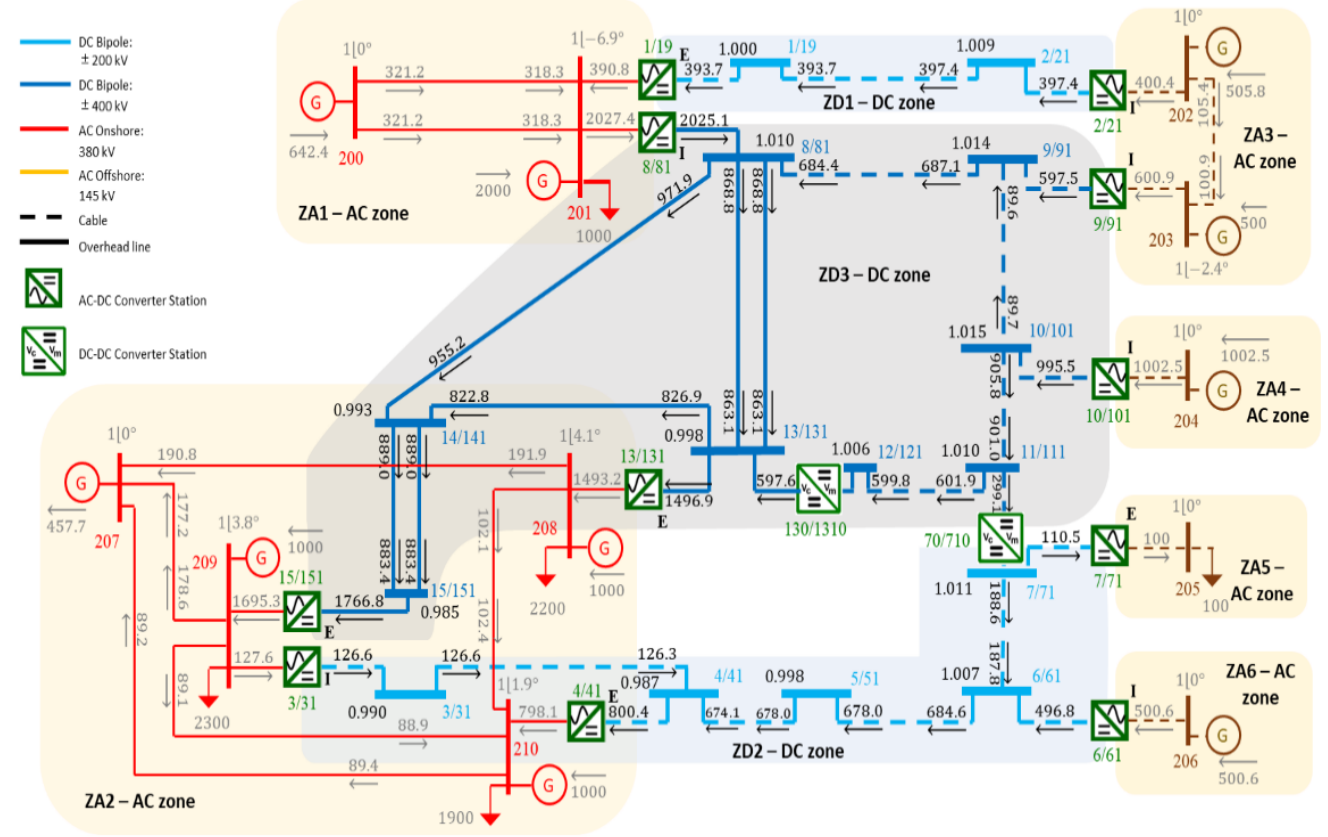

Figure 5. CIGRE B4 DC grid test system-power flow base case

The CIGRE B4 DC grid test is composed of the following zones:

- 2 onshore AC systems: AC zone ZA1 and AC zone ZA2, working at $380 \mathrm{kV}$.

- 4 offshore AC systems: AC zone ZA3 to AC zone ZA6, working at $145 \mathrm{kV}$.

- 3 VSC-DC systems: 2-terminal bipole HVDC zone ZD1 working at $\pm 200 \mathrm{kV}$, 4-terminal bipole HVDC zone ZD2 working at $\pm 200 \mathrm{kV}$ and 5-terminal bipole HVDC zone ZD3 working at $\pm 400 \mathrm{kV}$. A DC-DC converter station interconnect ZD2 and ZD3. 
Reliability parameters for converter stations and DC lines of the CIGRE B4 DC grid test system are presented in Table 3 based on data from [18].

Table 3. Reliability parameters for VSC-HVDC transmission lines

\begin{tabular}{ccc}
\hline Component & $\begin{array}{c}\mu \\
\text { (rep./year) }\end{array}$ & $\begin{array}{c}\lambda \\
\text { (out./year) }\end{array}$ \\
\hline Converter station & 75.60 & 1.76 \\
Transmission line & 22.82 & $0.166 \times \frac{\mathrm{L}}{100 \mathrm{~km}}$ \\
\hline
\end{tabular}

\subsection{Analysis of $\mathrm{N}-2$ contingencies}

The CIGRE B4 DC grid test system consists of 22 converter stations, half of them connected to the positive pole and the remaining connected to the negative pole, 26 DC lines and 2 DC-DC converters. A total of 1178 system contingencies are in the system based on the N-2 criteria: 50 single contingencies (a single converter station or a single DC pole) and 1128 double contingencies (two converter stations or two DC lines, or a converter station and a DC line). Based on (2), the probability of each state is computed. A DC bus has two numbers for its identification (example, DC bus $8 / 81$ ), one refers to the positive pole ( 8 in the example); and the other one refers to the negative pole ( 81 in the example).

\subsection{Remedial actions}

Remedial actions are implemented for all contingencies with convergence problems or operational limit violations. The power flow analysis fails to converge for 388 contingencies, and operating limits are violated for 600 contingencies out of 1178 total possible contingencies. Figures 6 and 7 show an application example of particular remedial actions, an outage of converter station 8 and converter station 9 occurs, so some bus voltages leave the operational frame ( 0.95 p.u. to 1.05 p.u.)

Table 4 shows the adjustments of DC bus voltages in each stage of the particular remedial actions. Table 5 shows the variations of power settings in converter stations. As seen in the application example, the application of the proposed remedial actions corrects system unbalances such that operational limit conditions are maintained.

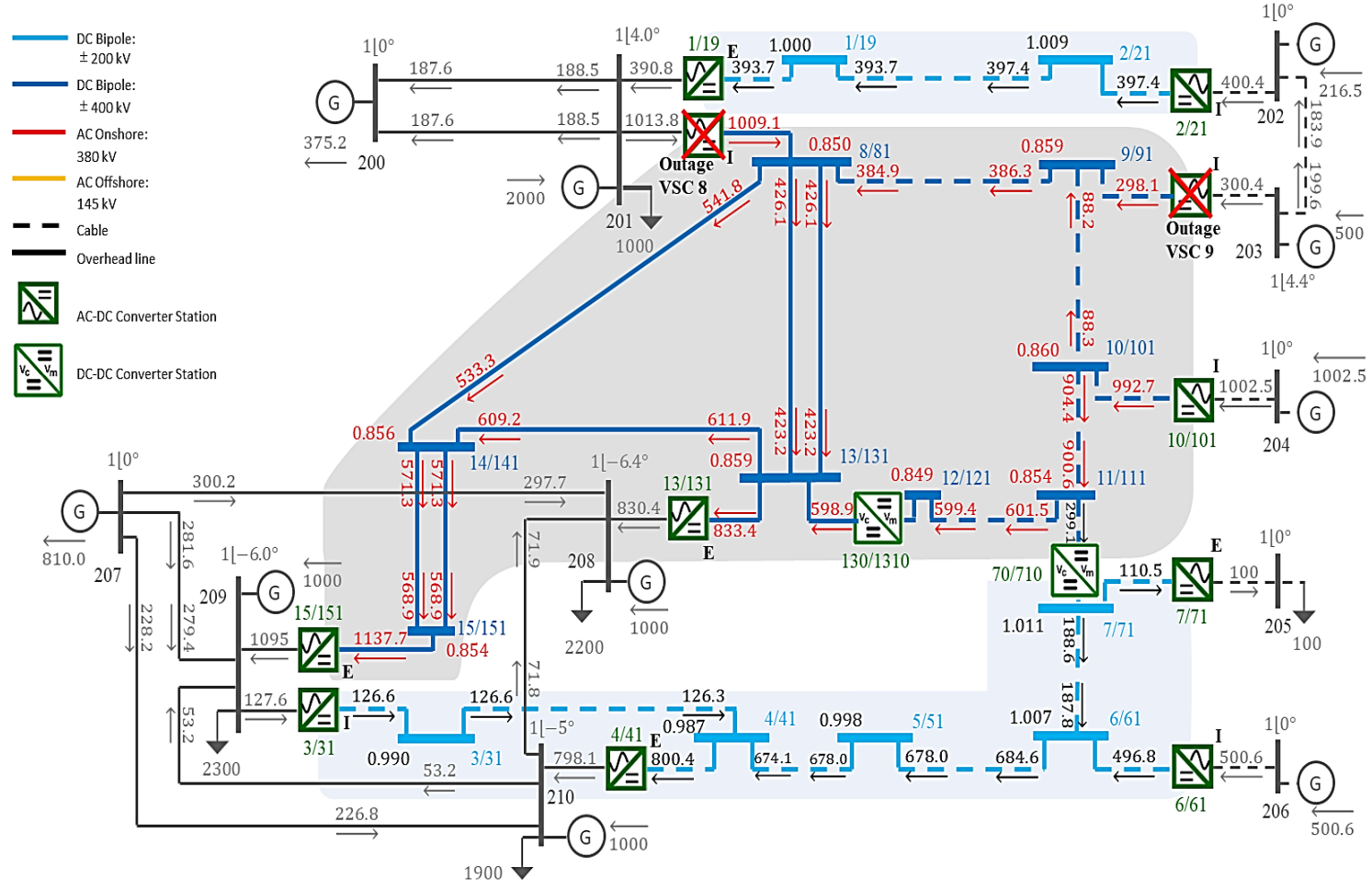

Figure 6. CIGRE B4 DC grid test system-power flow, outage of converters 8 and 9 


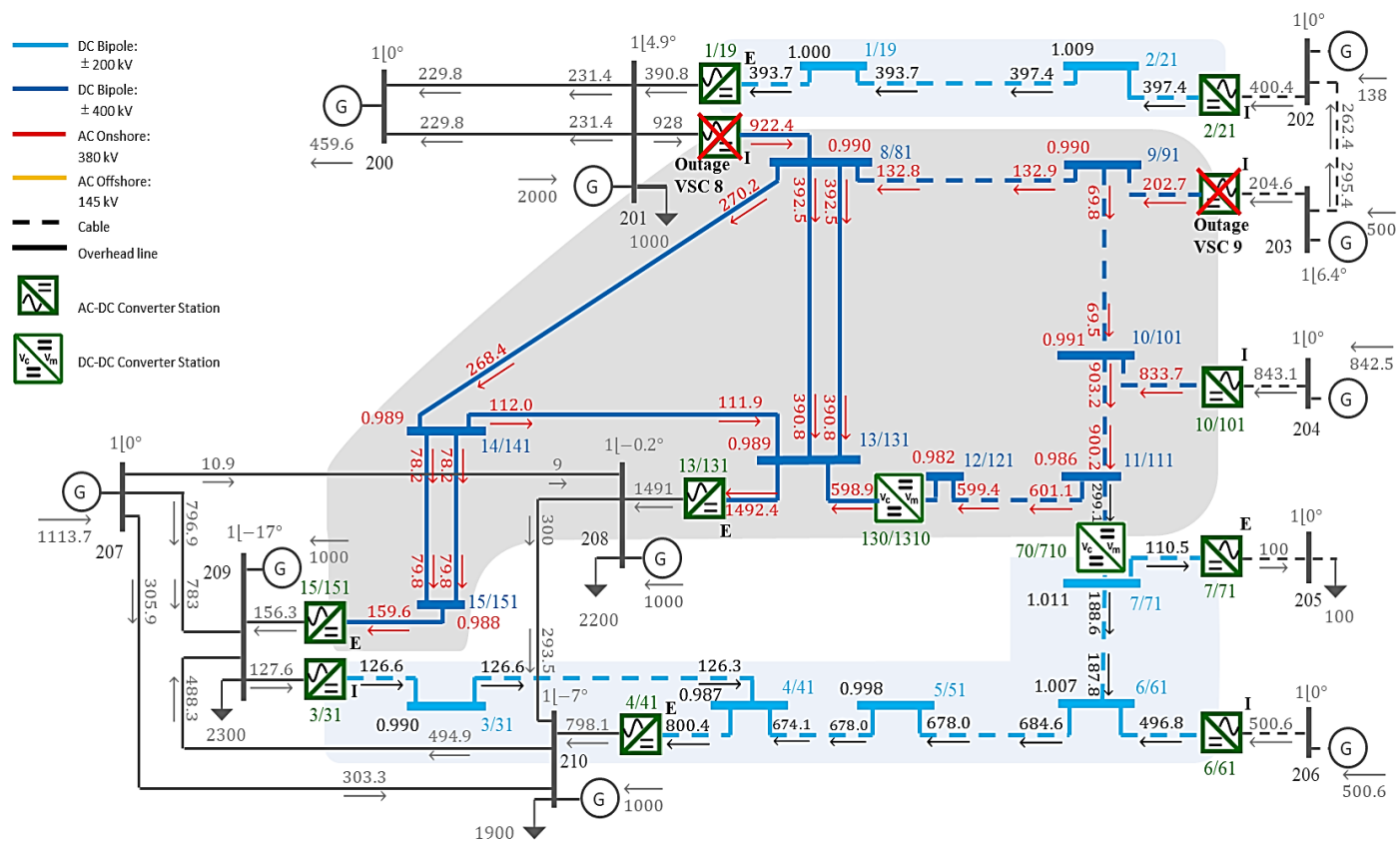

Figure 7. CIGRE B4 DC grid test system-power flow, outage of converters 8 and 9. Application of particular remedial actions

Table 4. Particular remedial actions-DC bus voltage adjustments-outage of converters 8 and 9

\begin{tabular}{clccc}
\hline & & Arithmetic power adjustment (p.u.) & Analytic power adjustment (p.u.) & Power balance (p.u.) \\
\hline DC Bus (pole +) & 8 & 0.858 & 0.899 & 0.990 \\
& 9 & 0.859 & 0.899 & 0.990 \\
& 10 & 0.860 & 0.901 & 0.991 \\
& 11 & 0.854 & 0.894 & 0.986 \\
& 12 & 0.849 & 0.890 & 0.982 \\
& 13 & 0.859 & 0.897 & 0.989 \\
& 14 & 0.856 & 0.901 & 0.989 \\
DC Bus (pole -) & 15 & 0.854 & 0.905 & 0.989 \\
& 91 & -1.010 & -1.010 & -1.010 \\
& 101 & -1.014 & -1.014 & -1.011 \\
& 111 & -1.015 & -1.015 & -1.009 \\
& 121 & -1.009 & -1.010 & -1.004 \\
& 131 & -1.006 & -1.006 & -1.001 \\
& 141 & -0.997 & -0.999 & -0.999 \\
& 151 & -0.993 & -1.001 & -1.001 \\
\end{tabular}

Table 5. Particular remedial actions-DC converter stations power adjustments-outage of converters 8 and 9

\begin{tabular}{cccc}
\hline DC Bus & Arithmetic power adjustment $(\mathrm{MW})$ & Analytic power adjustment $(\mathrm{MW})$ & Power balance $(\mathrm{MW})$ \\
\hline 8 & 0 & 0 & 0 \\
81 & -1200 & -1200 & -817 \\
9 & 0 & 0 & 0 \\
91 & -300 & -300 & -204 \\
10 & -500 & -500 & -500 \\
101 & -500 & -500 & -341 \\
13 & 84 & 1171 & 327 \\
131 & 750 & 1198 & 1198 \\
15 & 247 & 0 & 0 \\
151 & 851 & 0 & 0 \\
\hline
\end{tabular}

\subsection{Reliability results}

The reliability indices are computed for AC zones ZA1 to ZA6 and the DC grid. The left side of Table 6 shows the reliability indices for AC zones that injects/export power through the DC grid; while the right side shows the reliability indices for the zones that imports power from the DC grid. Finally, the performance indices of the DC grid are shown Table 7. 
Results show that main reason for energy non-supplied is the contingency in a converter station, despite having a bipolar system which increases reliability performance it does not provide enough support to meet the system power requirements when some kind of contingencies occurs. DC buses 8/81, 13/131 and

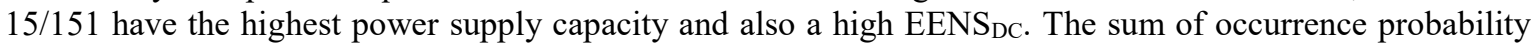
of the 1178 contingencies analyzed is $93.3 \%$. The EIR computed by the heuristic corrective actions has a difference of $0,5 \%$ respect to the EIR computed by OPF algorithms, as reported at [14]. The EENS obtained here is $26 \%$ larger than such obtained by OPF; while LOPEP is reduced in $12 \%$. The algorithms was run in an Intel Core i7 8th Gen, CPU@1,80 GHz (8 CPUs), 2,0 GHz, RAM 8 GB; the required time with heuristic actions was 0,28 compared with the time required by the OPF actions.

Table 6. Reliability indices

\begin{tabular}{|c|c|c|c|c|c|c|c|c|c|}
\hline \multicolumn{5}{|c|}{ AC Zones that injects/export power } & \multicolumn{5}{|c|}{$\mathrm{AC}$ zones that extracts/imports power } \\
\hline & $\begin{array}{c}\text { LOPIP } \\
(\%)\end{array}$ & $\begin{array}{c}\text { ENPIR } \\
\text { (occ./year) }\end{array}$ & $\begin{array}{l}\text { INS } \\
\text { (MW) }\end{array}$ & $\begin{array}{c}\text { EENI }_{\mathrm{DC}} \\
\text { (GWh/year) }\end{array}$ & & $\begin{array}{c}\text { LOPEP } \\
(\%)\end{array}$ & $\begin{array}{c}\text { ENPER } \\
\text { (occ./year) }\end{array}$ & $\begin{array}{l}\text { DNS } \\
\text { (MW) }\end{array}$ & $\begin{array}{c}\text { EENS }_{\mathrm{DC}} \\
(\mathrm{GWh} / \text { year })\end{array}$ \\
\hline ZA1 & 3 & 5 & 38 & 334 & ZA1 & 3 & 5 & 7 & 58 \\
\hline ZA2 & 3 & 5 & 2 & 19 & ZA2 & 10 & 14 & 72 & 626 \\
\hline ZA3 & 10 & 14 & 28 & 241 & ZA5 & 3 & 5 & 1 & 13 \\
\hline ZA4 & 8 & 10 & 43 & 373 & & & & & \\
\hline ZA6 & 3 & 5 & 8 & 74 & & & & & \\
\hline
\end{tabular}

Table 7. Reliability indices-global indices HVDC system

\begin{tabular}{cc}
\hline & HVDC network \\
\hline LOPEP (\%) & 16 \\
ENPER (occ./year) & 23 \\
DNS (MW) & 80 \\
EENS $_{\text {DC }}(\mathrm{GWh} /$ year) & 698 \\
EIR (\%) & 98.2 \\
\hline
\end{tabular}

\section{CONCLUSION}

A methodology of reliability evaluation for VSC-HVDC transmission grids based on a truncated $(\mathrm{N}-2)$ state enumeration is used. The HVDC grid of bipolar VSC-HVDC networks includes as basic components the converter station and the DC line. The methodology evaluates the performance of the HVDC grid by using two types of remedial actions implemented to solve grid energy unbalances and, useful for computing the reliability indices to evaluate the performance of the DC grid and its interaction with AC zones.

The results of the numerical analysis shown the expected behavior. In particular, remedial actions are effective for all contingencies when occurs a non-converge power flow or a system operating system limit violation, also reliability indices are consistent and are complementary to the classic reliability indices. The modelling technique is general and can be applied to any VSC-HVDC system. The methodology proposed can help to mitigate system emergencies and overstressed operating conditions, identify grid weaknesses and develop planning studies conceiving effective preventive actions.

Further research must be developed in order to make the reliability assessment of combined AC and DC systems. In the same way, planning methodologies of HVDC grids must be developed considering reliability aspects taking into account the function of this grid, to be a robust system to share large quantities of power; that is to say, the DC grid has power exchange functions with AC systems; both extraction and power injection. In addition, in the future hybrid HVAC/HVDC transmission systems, it is necessary to consider also the volatility of renewable non-conventional resources.

\section{REFERENCES}

[1] M. Bahrman and B. Johnson, "The ABCs of HVDC transmission technologies - An overview of high voltage direct current systems and applications," IEEE Power and Energy Magazine, vol. 5, no. 2, pp. 32-44, 2007.

[2] L. Michi et al., "New HVDC Technology in Pan-European power system planning," 2019 AEIT HVDC International Conference, Florence, Italy, 2019, pp. 1-6, doi: 10.1109/AEIT-HVDC.2019.8740544.

[3] Working Group B4-52, "HVDC grid feasibility study," CIGRE, Paris, France, Apr 2013.

[4] J. Sun et al., "Renewable Energy Transmission by HVDC Across the Continent: System Challenges and Opportunities," CSEE Journal of Power and Energy Systems, vol. 3 no. 4, pp. 353-364, Dec. 2017, doi: 10.17775/CSEEJPES.2017.01200. 
[5] D. Van Hertem, O. Gomis-Bellmunt and J. Liang, "HVDC grids for offshore and Supergrid on the future," IEEE press, John Wiley \& Sons, Inc., 2016.

[6] M. A. Rios and F. Acero, "Planning MTDC Grids based on Graphs Theory," International Journal of Electrical and Computer Engineering (IJECE), vol. 11, no. 1, pp. 37-46, Feb. 2021, doi: 10.11591/ijece.v11i1.pp37-46.

[7] K. Rudion and A. Orths, "Reliability investigations for a DC offshore power system," IEEE Power and Energy Society General Meeting 2013, PES-GM'13, 2013, doi: 10.1109/PESMG.2013.6672462.

[8] H. Xie, Z. Bie and G. Li, "Reliability-Oriented Network Planning for Meshed VSC-HVDC Grids," IEEE Transactions on Power Systems, vol. 34, no. 2, pp. 1342-1351, Mar. 2019, doi: 10.1109/TPWRS.2018.2878480.

[9] C. Wang, H.R. Chen, W.L. Pan and Z. Xu, "Reliability and economic evaluation of the China Southern power grid," IEEE Power System Conference and Exposition, PSCE, Atlanta, 2006, pp. 854-859, doi: 10.1109/PSCE.2006.296426.

[10] J. Guo, X. Wang and Y. Hou, "Reliability modeling and evaluation of VSC-HVDC transmission systems," IEEE/PES General Meeting, Conference and Exposition, National Harbor, Jul. 2014, pp. 1-5, doi: 10.1109/PESGM.2014.6939162.

[11] S. Li, Z. Wu and Y. Hua, "Reliability Evaluation of UHVDC Transmission Systems with Hierarchical Connection Mode," CSEE Journal of Power and Energy Systems, vol. 5, no. 1, pp. 73-81, Mar. 2019, doi: 10.17775/CSEEJPES.2017.00990.

[12] W. An et al., "Reliability evaluation and comparison for different topologies of VSC-HVDC distribution networks using analytical and simulation methods," 12th IET International Conference on AC and DC Power Transmission, ACDC 2016, Beijing, China, 2016.

[13] K. Linden et al., "Reliability study methodology for HVDC grids," Proc. CIGRE Paris Session 2010, paper WG B4-108, Paris, France, 2010.

[14] M. A. Rios, J. L. Vera and M. F. Perez, "Availability Assessment of VSC-HVDC Grids using OPF-based Remedial Actions," IET High Voltage, In-press, 2020, doi: 10.1049/hve.2020.0028.

[15] J. Beerten, "MatACDC 1.0 User's Manual," University of Leuven, 1992. [Online]. Available at: http://www.esat.kuleuven.be/electa/teaching/matacdc/, [accessed 1st July 2018].

[16] A. Beddard and M. Barnes, "VSC-HVDC Availability Analysis," The University of Manchester, Nov. 2011.

[17] G. Migliavacca, "Advanced Technologies for Future Transmission Grids," Springer, 2013.

[18] A. Camargo and M. A. Rios, "Reliability data and assessment for HVDC bipolar links," IEEE/PES Transmission and Distribution Conference and Exposition, Denver, April 2018, doi: 10.1109/TDC.2018.8440261.

[19] M. Poikilidis, E. Kontos and P. Bauer, "Design of the inner AC circuit of a DC hub for the interconnection of multiple HVDC lines," $45^{\text {th }}$ Annual Conference of the IEEE Industrial Electronics Society (IECON 2019), Lisbon, Portugal, vol. 1, 2019, pp. 1670-1677, doi: 10.1109/IECON.2019.8926855.

[20] S.B.K Venkata, V. Madhusudan and V. Ganesh, "Probabilistic Performance Index based Contingency Screening for Composite Power System Reliability Evaluatio," International Journal of Electrical and Computer Engineering (IJECE), vol. 8, no. 5, pp. 2661-2670, Oct. 2018, doi: 10.11591/ijece.v8i5.pp.2661-2670.

[21] J. Lu, W. Li and Y. Wei, "State enumeration technique combined with a labeling bus set approach for reliability evaluation of substation configuration in power systems," Electric Power Systems Research, vol. 77, no. 5-6, pp. 401-406, April 2007, doi: 10.1016/j.epsr.2006.04.001.

[22] Z. Zheng et al., "Reliability model and algorithm research on HVDC system and flexible HVDC system," The Journal of Engineering, vol. 2019, no. 16, pp. 2621-2624, 2019.

[23] W. Li, "Probabilistic Transmission System Planning," IEEE Press John Wiley \& Sons, NJ, USA, 2011.

[24] J. Gunda, G. P. Harrison and S. Z. Djokic, "Remedial actions for security constrain management of overstressed power systems," IEEE Transactions on Power Systems, vol. 33, no. 5, pp. 5183-5193, Sep. 2018, doi: 10.1109/TPWRS.2018.2796644.

[25] T. K. Vrana et al., "The CIGRE B4 DC grid test system," ELECTRA, no. 270, pp. 10-19, Oct. 2013.

[26] Working Group B4.72, "DC grid benchmark models for system studies," CIGRE, Paris, France, June 2020. 